\title{
Development and testing of a scale to evaluate diet according to the recommendations of the Dietary Guidelines for the Brazilian Population
}

\author{
Kamila Tiemann Gabe ${ }^{1,2, *}$ and Patricia Constante Jaime ${ }^{2,3}$ \\ 'Programa de Pós-Graduação em Nutrição em Saúde Pública, Faculdade de Saúde Pública, Universidade de São \\ Paulo, Av. Dr Arnaldo 715, Cerqueira César, São Paulo, SP 01246904 , Brazil: ${ }^{2}$ Núcleo de Pesquisas \\ Epidemiológicas em Nutrição e Saúde, Faculdade de Saúde Pública, Universidade de São Paulo, São Paulo, SP, \\ Brazil: ${ }^{3}$ Departamento de Nutrição, Faculdade de Saúde Pública, Universidade de São Paulo, São Paulo, SP, Brazil
}

Submitted 3 June 2018: Final revision received 5 December 2018: Accepted 21 December 2018: First published online 12 February 2019

\begin{abstract}
Objective: To develop and test a scale for healthy eating practices measurement according to the Dietary Guidelines for the Brazilian Population recommendations.

Design: Methodological study. The current Brazilian food-based dietary guideline highlights the importance of choosing foods, combining foods to create meals and modes of eating. These recommendations formed the main domains of the scale and served as a basis for the development of ninety-six items, each with a 4-point Likert response option. Content and face validity were tested. Exploratory factor analysis (EFA) and confirmatory factor analysis (CFA) were performed to determine construct validity. Internal consistency was determined using $\alpha$ and $\omega$ coefficients, and reproducibility was tested using test-retest.

Setting: Brazil.

Participants: A ten-member expert panel was used to assess content validity. Adults aged 18-60 years were included in the face validity ( $n$ 20), EFA ( $n$ 352), CFA and reliability tests ( $n$ 900).

Results: Of the ninety-six initial items, twenty-four were excluded and fifty-five were reworded following the content and face validations. EFA detected a fourdomain structure (Food choices, Modes of eating, Planning and Domestic organization), which explained $41 \%$ of the variance. CFA led to a final twentyfour-item model with acceptable goodness-of-fit indices and good reliability measures $(\alpha=0.77 ; \omega=0.83)$. Intraclass correlation coefficient for the total score $(0 \cdot 82)$ and analysis of the Bland-Altman plot suggested good reproducibility of the scale.

Conclusions: The scale presents good evidence of validity and reliability. This innovative study created a useful tool for evaluation of the impact of the Dietary Guidelines for the Brazilian Population.
\end{abstract}

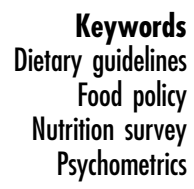

Dietary guidelines are instruments through which countries establish recommendations for healthy eating and are aimed at promoting autonomy of healthy food choices by individuals and communities ${ }^{(1)}$. In addition to their applicability in health communication, dietary guidelines also aim to support public policies to promote adequate and healthy diets in different sectors of government, including health, education, industry and agriculture $^{(1,2)}$.

The construction of the second edition of the Dietary Guidelines for the Brazilian Population (called the
'Guide' hereafter) published by the Brazilian Ministry of Health in 2014 was based on an expanded paradigm of diet and its relationship with health ${ }^{(3)}$. Beyond the biological dimension, this document also includes cultural, social and environmental aspects as determinants of an adequate and healthy $\operatorname{diet}^{(4)}$. In addition, its recommendations are based on the logic of foods and food groups rather than isolated nutrients; this approach is considered more appropriate for understanding the relationship between diet and current epidemiological scenarios $^{(4,5)}$. The adoption of systemic perspectives in 
dietary guidelines has also been observed recently in other countries, including Germany, Qatar and Sweden ${ }^{(6)}$.

An innovative aspect of the Guide is the incorporation of the food processing perspective ${ }^{(7)}$. The main recommendations were based on the NOVA groups; NOVA is a classification system that groups foods according to the nature, extent and purpose of the processing to which they have been subjected ${ }^{(8)}$. The adoption of NOVA was motivated by population-based studies conducted over the last decade that evidenced the growing tendency for consumption of ultra-processed foods by the Brazilian population $^{(9,10)}$ and the negative impact of these foods on the nutritional quality of the diet and health outcomes $^{(11-14)}$.

Unlike commonly adopted dietary guideline approaches $^{(6)}$, the Guide recommendations are not presented in terms of the frequency or number of food portions but instead use terms such as 'prefer', 'avoid' and 'always when possible'. In addition, illustrations of healthy meal options based on the diet of one-fifth of the Brazilian population with the lowest share of ultraprocessed foods according to data from a national survey are shown ${ }^{(4,15)}$. These characteristics are intended to facilitate dialogue with the population, public managers and health professionals (other than nutritionists).

With a view towards implementing dietary guidelines, the FAO recommends that countries develop strategies to disseminate their messages ${ }^{(1)}$. However, the diversity of formats and approaches adopted in these documents imply that there is no universal recommendation for their implementation and that this process should be defined by each country according to its local reality. Additionally, countries should institute mechanisms for monitoring and evaluating both the implementation process and the impact of these instruments on food practices of their populations; this step has been reinforced in technical documents from the $\mathrm{FAO}^{(1,2,16)}$.

Although innovative, the expanded approach to healthy eating proposed by the Guide presents a challenge for the evaluation of its impact on the Brazilian population. Unlike the recommendations of its first edition, which were based on portions of food groups and therefore evaluable through traditional food consumption tools such as $24 \mathrm{~h}$ recall, as conducted in a study by Verly et $a l .{ }^{(17)}$, the challenge of the new edition lies in the selection and use of appropriate tools in line with the content of its recommendations. Because the importance of using validated tools for the evaluation of dietary guidelines is recognized ${ }^{(18)}$, the present study aimed to develop and test the validity and reliability a scale for measuring healthy eating practices according to the recommendations of the current Brazilian food-based dietary guidelines.

\section{Materials and methods}

The current study is a methodological study based on knowledge of psychometry, which is a science that studies the measurement of non-directly observable phenomena (i.e. psychological phenomena) that can be characterized using a set of other attributes ${ }^{(19)}$. This feature can be useful for the construction of instruments for diet measurement in relation to the adoption of paradigms that consider diet a result of complex relationships among different determinants. A self-administered scale is proposed for the Brazilian adult population (18-60 years old).

The adopted route is composed of three phases, which are described below.

\section{Phase 1: Structuring the theoretical basis of the scale and elaboration of the items}

The Guide is systematized into a document with five chapters. The first chapter presents the principles that guide its elaboration. The following chapters present recommendations for food choices (Chapter 2), how to combine foods in the form of meals (Chapter 3) and modes of eating (Chapter 4). The last chapter exposes possible obstacles to adherence to the recommendations and suggests ways to overcome them ${ }^{(3)}$. Because they deal specifically with recommendations, Chapters 2, 3 and 4 of the Guide were selected to compose the domain content of the scale. Following systematic reading of the three selected chapters, all of their recommendations were extracted regardless of whether they were made explicit in the form of sentences or illustrations.

Based on these recommendations, a pool of sentences (items) illustrating eating practices either in line with or in opposition to the Guide contents was created. For these items, the respondents indicated whether they were represented in their daily eating practices through a 4-point Likert scale ('strongly agree', 'agree', 'disagree', 'strongly disagree'). An even number of response options was adopted with the purpose of avoiding not only the central tendency bias but also a possible variability in the participants' interpretations of a midpoint in Likert scales (such as 'no opinion', 'unsure' or 'neutral') ${ }^{(20)}$. Therefore, the respondents were encouraged to analyse the sentence with greater care and then decide on a positive or negative stance $^{(19)}$.

\section{Phase 2: Validity tests}

Content validity

This step aimed to identify whether the items adequately contemplated the contents of the scale domain ${ }^{(21)}$. Ten experts in the field of nutritional epidemiology and/or food consumption were invited to participate in a panel. Researchers affiliated with educational institutions (public 
universities across the country) who had recent scientific publications related to the Guide's content at the time of panel selection, as well as public managers who participated in the Guide's elaboration process, identified in a name list published within the Guide, were selected ${ }^{(22,23)}$.

Through an electronic form, the judges assigned a score from 1 to 4 for the clarity, relevance and pertinence of each item. From the answers obtained, the content validity index of the items $\left(\mathrm{CVI}_{\mathrm{i}}\right)$ was calculated based on the averages between the percentages of scores 3 and 4 for each of its three attributes, and the total $\mathrm{CVI}\left(\mathrm{CVI}_{\mathrm{t}}\right)$ was obtained from the mean of the CVI values of the items. A CVI $>0.8$ was considered adequate ${ }^{(23)}$. During the panel, the judges were also able to comment on each item or suggest the inclusion of new items in open fields intended for that purpose.

\section{Face validity}

This step aimed to assess whether the instrument was adequate and understandable for its target audience ${ }^{(21)}$. The instrument was pre-tested with twenty adult users of a public primary health care (PHC) service located in the city of São Paulo, SP, Brazil, because this type of service in Brazil attends a wider and heterogenic audience ${ }^{(24)}$. Individuals were selected through a purposive approach ${ }^{(25)}$ in order to guarantee the representativeness of people from different educational levels and age groups. The application of the instrument was followed by a brief interview with each individual to verify his/her level of understanding about the instrument.

\section{Construct validity}

This step aimed to identify the structural components of the construct 'healthy eating practices according to the Guide' and the extent to which the set of items was correlated with these components ${ }^{(19,21,26)}$. Based on the theoretical basis (delimited in phase 1), construct validity was performed through factor analysis in two steps: exploratory factor analysis (EFA) and confirmatory factor analysis (CFA). R-Studio software version 3.4.3 was used to analyse the data ${ }^{(27)}$

Exploratory step. An EFA was used to identify the possible dimensions underlying the data (latent variables) and to reduce the number of items ${ }^{(21,28,29)}$. The data were collected from a convenience sample of users of two PHC services of São Paulo, SP, Brazil. People were invited by an interviewer to respond to the scale during their time in the PHC service waiting room. The recruitment aimed to achieve similar proportions of gender and age groups. An estimated sample size of 350 was calculated based on at least five to ten observations per variable ${ }^{(26,28)}$. The adequacy of the sample was tested using the Kaiser-MeyerOlkin (KMO) indicator (range 0 to 1 , values $>0.5$ were considered acceptable) and Bartlett's sphericity test $(P<0.05 \text { was considered acceptable })^{(28,30)}$. To determine the number of factors to be extracted, the Kaiser-Guttman criterion (eigenvalue $>1.00$ ) was adopted. To support the decision regarding the number of factors to be maintained after extraction and interpretation, the theoretical and practical plausibility of the obtained results were considered $^{(28,29)}$.

The EFA was executed through the $\mathrm{R}$ package 'Psych',(31). A polychoric correlation matrix was created that was suitable for ordinal categorical variables, such as Likert scales ${ }^{(29,32)}$. The factors were extracted using the principal axis as a factor method and rotation of the OBLIMIN type. Items with non-significant factor loadings (less than $|0.4|$ ) and those with significant loadings for more than one factor (cross-loading) were excluded ${ }^{(26)}$. The item analysis and exclusion processes were repeated successively until a stable factorial structure was obtained (i.e. all items had factorial loads greater than $|0.4|$ in only one factor). The generated solutions were analysed from the theoretical significance perspective, which supported determination of the best model.

Confirmatory step. CFA was used to test the hypothesis that the predefined model was adequate to measure the construct in question, in this case the healthy eating practices according to the Guide recommendations. The sample consisted of 900 (more than ten observations per variable, thus a sufficiently large sample size) adults living in the Brazilian territory. The data collection was performed using an online platform by a company specialized in Internet research that has a panel of more than 500000 respondents from all five Brazilian macro-regions with different socio-economic statuses and age groups. The questionnaire was programmed on the company's platform by the researchers, and the recruitment was randomly performed from the panel of respondents. Internal controls were used to guarantee the data consistency (we excluded answers that were provided quicker than the time necessary for $95 \%$ of the respondents to complete the questionnaire and those in which the respondents did not meet the age criteria).

The CFA was executed through the $\mathrm{R}$ package lavaan ${ }^{(33)}$. The diagonally weighted least-squares estimator was used, which is appropriate for categorical variables $^{(29,34)}$. The evaluation of model quality was based on the following aspects suggested by Brown ${ }^{(29)}$ : (i) inspection of the goodness-of-fit indices; (ii) the presence of tension points, which were evaluated using the modification indices (MI) in the present study; and (iii) the interpretability and statistical significance of the factor loadings. The following goodness-of-fit indicators were considered: root-mean-square error of approximation (RMSEA); standardized root-mean-square residual (SRMR); comparative fit index (CFI); and Tucker-Lewis index (TLI). The RMSEA was evaluated according to the criteria of Browne and Cudeck ${ }^{(35)}$, in which values $\leq 0.08$ indicated an adequate fit, values between 0.08 and $0 \cdot 10$ indicated a mediocre fit and values $>0.10$ indicated a poor fit. For the CFI, TLI and SRMR analyses, the 
following cut-off points were used: CFI $\geq 0 \cdot 95$; TLI $\geq 0 \cdot 90$; and SRMR $<0 \cdot 80^{(36)}$.

Total information curves were generated for the full scale and its subscales. These curves indicate the precision with which the scale and its subscales is able to discriminate between individuals as a function of the score distribution (in the $Z$-score scale) ${ }^{(37)}$.

\section{Phase 3: Reliability tests}

The reliability of the instrument was evaluated based on two aspects: internal consistency and reproducibility.

For the internal consistency evaluation, Cronbach's $\alpha$ coefficients were calculated for the scale and its four subscales. Because the interpretability of Cronbach's $\alpha$ can be restricted in multidimensional scales, McDonald's $\omega$ was also calculated for the total scale since it is considered a reliability index with a lower risk of over- or underestimation of reliability in these cases ${ }^{(38-40)}$. For both measures, values equal to or greater than 0.7 were considered satisfactory ${ }^{(26)}$.

A random sub-sample was obtained from individuals who participated in the confirmatory step of construct validation and responded again to the scale $30 \mathrm{~d}$ after the first data collection. The intraclass correlation coefficient (ICC; single-measurement, absolute agreement, two-way mixed-effect model) was calculated to assess test-retest reliability both for the total score and for each single item. ICC values less than 0.4 were interpreted as poor reliability; 0.4 to 0.75 as fair to good; and greater than 0.75 as excellent $^{(41,42)}$. The Bland-Altman plot was used to test the absence of systematic errors between the total score of the two time point measures ${ }^{(43)}$.

\section{Results}

When structuring the theoretical basis and elaboration of the items, fifty-one recommendations were identified between Chapters 2, 3 and 4 of the Guide. From these recommendations, ninety-six items were formulated. During the content validity step, twenty-three redundant items were excluded and a new item was added (resulting in a subtotal of seventy-four items); additionally, the wording of fifty-five other items was changed. The $\mathrm{CVI}_{\mathrm{t}}$ was 0.93 . In the face validity step, two redundant items were excluded (new subtotal of seventy-two items) and fifteen items were changed. The fifty-one recommendations and the set of seventy-two items kept after these steps can be consulted in the online supplementary material.

Table 1 presents the sociodemographic characteristics of the participants of the exploratory ( $n$ 352) and confirmatory (ninety-three responses were unconsidered; $n$ 900) construct validity steps. The average age and the proportion of women were slightly higher in the
Table 1 Sociodemographic characteristics of the adults aged 1860 years who participated in the construct validity assessment, according to step (exploratory or confirmatory), of the scale for measuring healthy eating practices according to the Dietary Guidelines for the Brazilian Population recommendations

\begin{tabular}{|c|c|c|c|c|c|}
\hline \multirow[b]{2}{*}{ Variable } & \multicolumn{2}{|c|}{ Exploratory step } & \multicolumn{2}{|c|}{ Confirmatory step } & \multirow[b]{2}{*}{$P$ value* } \\
\hline & Mean & SD & Mean & SD & \\
\hline \multirow[t]{2}{*}{ Age (years) } & $40 \cdot 1$ & $12 \cdot 2$ & 33.5 & 11.4 & $<0.001$ \\
\hline & $n$ & $\%$ & $n$ & $\%$ & $P$ value \\
\hline Gender & & & & & $<0.05$ \\
\hline Female & 206 & 58.5 & 470 & $52 \cdot 2$ & \\
\hline Male & 146 & 41.5 & 430 & $47 \cdot 8$ & \\
\hline Region of origin & & & & & $<0.001$ \\
\hline Midwest & 3 & 0.9 & 81 & $9 \cdot 0$ & \\
\hline Northeast & 83 & $24 \cdot 1$ & 235 & $26 \cdot 1$ & \\
\hline North & 4 & $1 \cdot 2$ & 47 & $5 \cdot 2$ & \\
\hline Southeast & 240 & 69.8 & 407 & $45 \cdot 2$ & \\
\hline South & 14 & $4 \cdot 1$ & 130 & 14.4 & \\
\hline Total & 352 & 100 & 900 & 100 & \\
\hline
\end{tabular}

${ }^{*}$ From $X^{2}$ test.

†From Student's $t$ test.

exploratory step than in the confirmatory step. The samples were also different in terms of region of origin. Both steps had a higher concentration of individuals from the Southeast region of the country, followed by the Northeast region. However, there were more individuals from other regions of the country in the confirmatory step.

In the EFA, the tests confirmed the sampling adequacy $(\mathrm{KMO}=0.63$; Bartlett sphericity test, $P<0 \cdot 05)$. Six factors with eigenvalues $>1.00$ (Fig. 1) were identified. The results of the EFA with extraction of six factors did not present theoretical plausibility. Therefore, analyses were also conducted with extractions of five and four factors for comparison and to choose the best model. The four-factor model was chosen, because it had the most theoretical practical significance. This solution kept thirty-four of the seventy-two initial items and explained $41 \%$ of the variance in the data set (excluded items are highlighted in the online supplementary material).

The extracted factors were interpreted based on the items that composed them and the recommendations of the Guide from which they were derived. From this interpretation, the factors were understood as dimensions of the Guide; names were given and brief descriptions of the hypothetical construct measured by each factor were developed (Table 2).

We observed that the Choices dimension grouped items which were derived almost exclusively from the recommendations of the second chapter of the Guide (Choosing foods), which justifies its name. The Modes and Organization dimensions mostly retained items related to the fourth chapter of the Guide (Modes of eating), whereas Planning was formed by a combination of items from the three chapters that comprised the scale domain. 


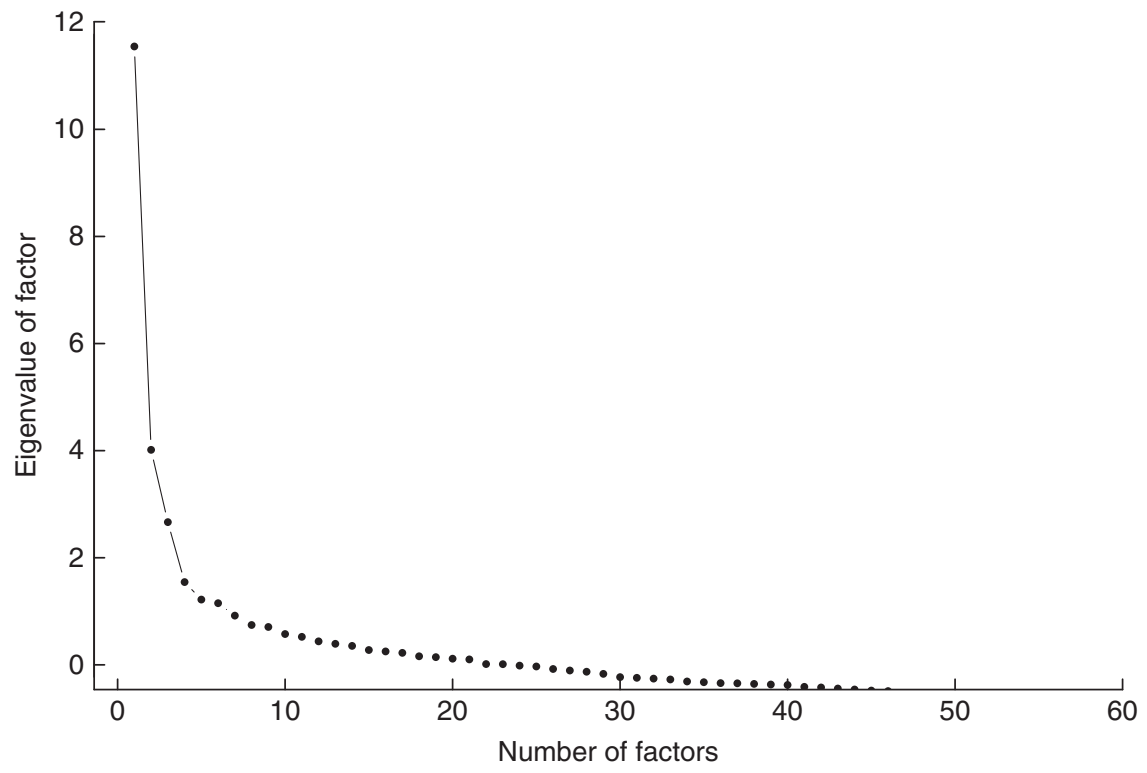

Fig. 1 Number of factors with eigenvalue $>1.00$ in the exploratory factor analysis of the scale for measuring healthy eating practices according to the Dietary Guidelines for the Brazilian Population recommendations

In the CFA, the initial model derived from the EFA returned some empty cells in the bivariate table of correlation matrix. This result indicated perfect correlations between two variables and thus an inadmissible factor solution. To make the model admissible, nine items were excluded.

The model generated after the exclusion of these items had unsatisfactory goodness-of-fit indices: $\chi_{(269)}^{2}=2954 \cdot 180, P<0.001 ;$ RMSEA $=0.105$ (90\% CI 0.102, $0 \cdot 109) ; \quad \mathrm{CFI}=0.879 ; \quad \mathrm{TLI}=0.866 ; \quad \mathrm{SRMR}=0.095$. In this model, one item of the Organization dimension presented a non-significant factor loading (0.16). Exclusion of this item improved the goodness-of-fit indices $\left(\chi_{(264)}^{2}=2349.072\right.$, $P<0.001 ;$ RMSEA $=0.103$ (90\% CI 0.099, 0.107), $P<0 \cdot 001$; $\mathrm{CFI}=0.893 ; \mathrm{TLI}=0.879 ; \mathrm{SRMR}=0.091$ ).

The MI inspection of this new model indicated that two of the items of the Modes dimension were also correlated with other factors (cross-loading). Supported by the theory, an item related to 'eating at the table' (item 13) was also attributed to the Organization dimension
$(\mathrm{MI}=562.93)$, and another item related to 'eating slowly' (item 9) was also attributed to the Planning dimension $(\mathrm{MI}=449.8)$, in which higher factor loadings were obtained. The goodness-of-fit indices of the final model indicated good fits: $\chi_{(222)}^{2}=1326.37 ; P<0.001 ;$ RMSEA $=$ 0.074 (90\% CI 0.071, 0.078), $P<0.001 ; \mathrm{CFI}=0.944 ; \mathrm{TLI}=$ 0.937 ; SRMR $=0.067$. This final set of items is shown in Table 3 both in Portuguese (original language) and English.

Figure 2 presents a diagram of the model showing the factor loadings of the items and the correlations between dimensions. Positive moderate correlations were found between the Planning and Organization dimensions $(r=0.69, P<0 \cdot 001)$ and between the Modes and Choices dimensions $(r=0.52, P<0.001)$. The other correlations between dimensions were negligible.

The Planning and Organization dimensions are characterized as positive dimensions, whereas the Modes and Choices dimensions are characterized as negative (i.e. they measure constructs opposed to the Guide

Table 2 Factors obtained in the exploratory factor analysis of the scale for measuring healthy eating practices according to the Dietary Guidelines for the Brazilian Population recommendations and the respective measured dimensions according to the interpretation of their item set

\begin{tabular}{|c|c|c|c|}
\hline Factor & Dimension & Short name* & Description \\
\hline 1 & Planning & Planning & $\begin{array}{l}\text { Meal planning in terms of occurrence and composition, including healthy options. This } \\
\text { dimension seems to be related to the dedication undertaken by individuals to their } \\
\text { diet }\end{array}$ \\
\hline 2 & Domestic organization & Organization & $\begin{array}{l}\text { Existence of a domestic organization for the supply and preparation of food in the } \\
\text { domicile. For those who share housing with others, collective involvement is an } \\
\text { important attribute in this dimension }\end{array}$ \\
\hline 3 & Eating modes & Modes & $\begin{array}{l}\text { Conditions in which the meals are consumed in terms of suitability of the environment } \\
\text { and the time and attention dedicated to the act of eating }\end{array}$ \\
\hline 4 & Food choices & Choices & $\begin{array}{l}\text { Inclusion of ultra-processed foods in the habitual food consumption of individuals. This } \\
\text { consumption is expressed in the substitution of main meals, the habit of consuming } \\
\text { sugary beverages and the consumption of snacks between meals }\end{array}$ \\
\hline
\end{tabular}

${ }^{\star}$ The short name has been used throughout the text for simplification. 
Table 3 Final set of twenty-four items in both the Portuguese (original language) and English (translated)* scale for measuring healthy eating practices according to the Dietary Guidelines for the Brazilian Population recommendations and intraclass correlation coefficient (ICC) for each item and for the total score

\begin{tabular}{|c|c|c|c|c|}
\hline Item & Portuguese (original language) & English (translated) & ICC & $95 \% \mathrm{Cl}$ \\
\hline Item 1 & Costumo comer fruta no café da manhã & I usually eat fruit at breakfast & 0.61 & $0.47,0.72$ \\
\hline Item 2 & $\begin{array}{l}\text { Na minha casa é comum usarmos farinha de } \\
\text { trigo integral }\end{array}$ & $\begin{array}{l}\text { We commonly use whole-meal wheat } \\
\text { flour at home }\end{array}$ & 0.54 & $0.38,0.66$ \\
\hline Item 3 & $\begin{array}{l}\text { Costumo variar o consumo de feijão por ervilha, } \\
\text { lentilha ou grão de bico }\end{array}$ & $\begin{array}{l}\text { I usually vary the consumption of beans } \\
\text { among peas, lentils and chickpeas }\end{array}$ & 0.55 & $0.39,0.67$ \\
\hline Item 4 & Costumo planejar as refeições que farei no dia & I usually plan my daily meals & 0.55 & $0.40,0.67$ \\
\hline Item 5 & $\begin{array}{l}\text { Costumo levar algum alimento comigo para } \\
\text { caso eu sinta fome ao longo do dia }\end{array}$ & $\begin{array}{l}\text { I usually carry some food with me in case } \\
\text { I get hungry during the day }\end{array}$ & $0 \cdot 61$ & $0.47,0.72$ \\
\hline Item 6 & $\begin{array}{l}\text { Quando escolho frutas, legumes e verduras, } \\
\text { dou preferência para aqueles que são } \\
\text { orgânicos }\end{array}$ & $\begin{array}{l}\text { When I choose fruits and vegetables, } \\
\text { I prefer those that are organic }\end{array}$ & 0.58 & $0.43,0.70$ \\
\hline Item 7 & $\begin{array}{l}\text { Quando escolho frutas, verduras e legumes, } \\
\text { dou preferência para aqueles que são de } \\
\text { produção local }\end{array}$ & $\begin{array}{l}\text { When I choose fruits and vegetables, } \\
\text { I prefer those that come from local } \\
\text { farmers }\end{array}$ & 0.46 & $0.29,0.60$ \\
\hline Item 8 & $\begin{array}{l}\text { Quando eu faço pequenos lanches ao longo do } \\
\text { dia, costumo comer frutas ou castanhas }\end{array}$ & $\begin{array}{l}\text { When I eat small meals during the day, } \\
\text { I usually have fruits or nuts }\end{array}$ & 0.54 & $0.39,0.67$ \\
\hline Item 9 & Procuro realizar as refeições com calma & I try to eat slowly & 0.55 & $0.40,0.67$ \\
\hline Item 10 & $\begin{array}{l}\text { Costumo comprar alimentos em feiras livres ou } \\
\text { feiras de rua }\end{array}$ & I usually buy foods at street market & 0.52 & $0.36,0.65$ \\
\hline Item 11 & $\begin{array}{l}\text { Na minha casa compartilhamos as tarefas que } \\
\text { envolvem o preparo e consumo das refeições }\end{array}$ & $\begin{array}{l}\text { We share tasks which involve the } \\
\text { preparation and consumption of foods } \\
\text { at home }\end{array}$ & 0.45 & $0.28,0.59$ \\
\hline Item 12 & $\begin{array}{l}\text { Costumo participar do preparo dos alimentos na } \\
\text { minha casa }\end{array}$ & $\begin{array}{l}\text { I usually engage in meal preparation at } \\
\text { home }\end{array}$ & 0.68 & $0.56,0.77$ \\
\hline Item 13 & $\begin{array}{l}\text { Costumo fazer minhas refeições sentado(a) à } \\
\text { mesa }\end{array}$ & $\begin{array}{l}\text { I usually eat breakfast/lunch/dinner at the } \\
\text { table }\end{array}$ & 0.53 & $0.37,0.65$ \\
\hline Item 14 & $\begin{array}{l}\text { Costumo pular pelo menos uma das refeições } \\
\text { principais (almoço e jantar) }\end{array}$ & $\begin{array}{l}\text { I usually skip at least one of the main } \\
\text { meals (lunch or dinner) }\end{array}$ & 0.57 & $0.42,0.69$ \\
\hline Item 15 & $\begin{array}{l}\text { Costumo fazer minhas refeições sentado(a) no } \\
\text { sofá da sala ou na cama }\end{array}$ & $\begin{array}{l}\text { I usually eat breakfast/lunch/dinner } \\
\text { seated on the couch in the living room } \\
\text { or in bed }\end{array}$ & 0.51 & $0.36,0.65$ \\
\hline Item 16 & $\begin{array}{l}\text { Costumo fazer as refeições na minha mesa de } \\
\text { trabalho ou estudo }\end{array}$ & $\begin{array}{l}\text { I usually eat breakfast/lunch/dinner at my } \\
\text { work's or study's desk }\end{array}$ & 0.50 & $0.34,0.64$ \\
\hline Item 17 & $\begin{array}{l}\text { Aproveito o horário das refeições para resolver } \\
\text { outras coisas e acabo deixando de comer }\end{array}$ & $\begin{array}{l}\text { I deal with personal issues during meal } \\
\text { time, and therefore I usually end up not } \\
\text { eating anything }\end{array}$ & 0.57 & $0.42,0.69$ \\
\hline Item 18 & $\begin{array}{l}\text { Quando bebo café ou chá, costumo colocar } \\
\text { açúcar }\end{array}$ & $\begin{array}{l}\text { When I drink coffee or tea, I usually add } \\
\text { sugar }\end{array}$ & 0.67 & $0.55,0.77$ \\
\hline Item 19 & $\begin{array}{l}\text { Costumo trocar a comida do almoço ou jantar } \\
\text { por sanduíches, salgados ou pizza }\end{array}$ & $\begin{array}{l}\text { I usually take sandwiches, savoury } \\
\text { snacks or pizza for lunch or dinner } \\
\text { instead of freshly prepared dishes }\end{array}$ & 0.66 & $0.54,0.76$ \\
\hline Item 20 & Costumo beber refrigerante & I usually drink soft drinks & 0.75 & $0.65,0.82$ \\
\hline Item 21 & $\begin{array}{l}\text { Tenho o hábito de 'beliscar' no intervalo entre as } \\
\text { refeições }\end{array}$ & I often snack between meals & 0.49 & $0.33,0.63$ \\
\hline Item 22 & $\begin{array}{l}\text { Costumo frequentar restaurantes fast-food ou } \\
\text { lanchonetes }\end{array}$ & $\begin{array}{l}\text { I usually go to fast-food restaurants or } \\
\text { snack bars }\end{array}$ & 0.62 & $0.48,0.72$ \\
\hline Item 23 & $\begin{array}{l}\text { Costumo beber sucos industrializados, como de } \\
\text { caixinha, em pó, garrafa ou lata }\end{array}$ & $\begin{array}{l}\text { I usually drink industrialized juices, such } \\
\text { as those which are powdered or the } \\
\text { ones that are packed in boxes, bottles } \\
\text { or tins }\end{array}$ & 0.64 & $0.51,0.75$ \\
\hline Item 24 & $\begin{array}{l}\text { Costumo comer balas, chocolates e outras } \\
\text { guloseimas. }\end{array}$ & $\begin{array}{l}\text { I usually eat candies, chocolates and } \\
\text { other sweets }\end{array}$ & 0.40 & $0.21,0.55$ \\
\hline Total score & - & - & 0.82 & $0.74,0.87$ \\
\hline
\end{tabular}

${ }^{*}$ The translation of the items was made by two independent translators. A third translator resolved the discrepancies between them in order to achieve the better conceptual equivalence.

recommendations). Notably, the two items with crossloading present negative factor loadings in the Modes dimension but positive factor loadings in the Organization and Planning dimensions, which reflect the opposite characters between dimensions. Therefore, the scores assigned to the responses of the items in the Choices and Modes dimensions must be reversed to ensure that the sum of the score is determined properly, as shown in Table 4.
Figure 3 illustrates the total information curves of the full scale and each of the subscales. All curves have a characteristic plateau format, which indicates that they are accurate for individuals with different score ranges. The full scale (Fig. 3(a)) and the Planning and Choices subscales (Figs 3(b) and 3(e)) are accurate between individuals with scores up to $2 \mathrm{sD}$ below or above the mean, indicating a good discrimination capacity even among 


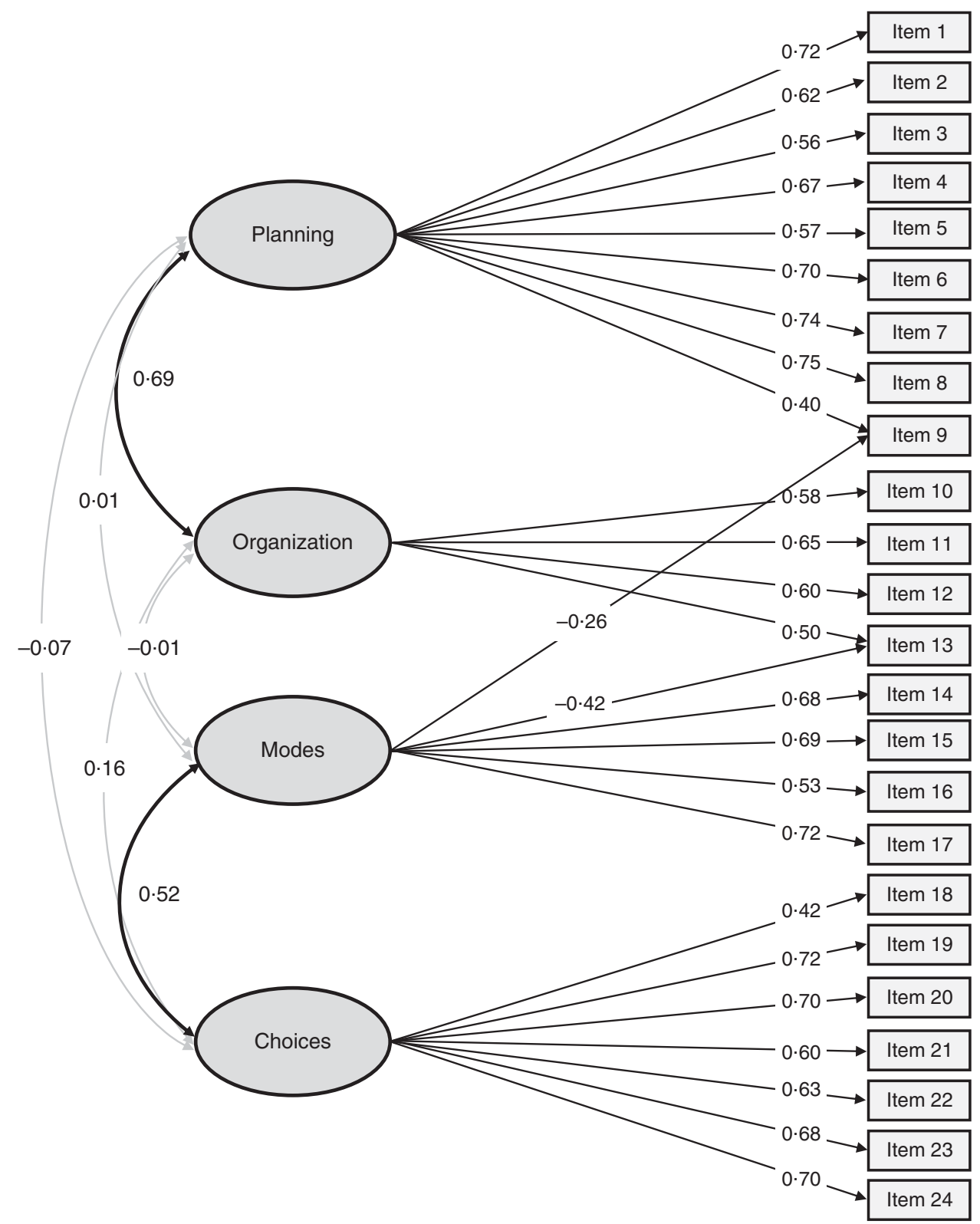

Fig. 2 Diagram representing the model of the final scale for measuring healthy eating practices according to the Dietary Guidelines for the Brazilian Population recommendations, showing the factor loadings of the items and the correlations between dimensions

individuals who have more distal scores. The Organization and Modes subscales have slightly shifted curves, so their discrimination capacity is more limited for specific score ranges (Figs 3(c) and 3(d)).

Table 4 Instructions for the sum of the individual scores for the Choices and Modes dimensions of the scale for measuring healthy eating practices according to the Dietary Guidelines for the Brazilian Population recommendations

\begin{tabular}{lccccc}
\hline \multicolumn{2}{c}{ Response option of the Likert scale } & & \multicolumn{2}{c}{ Items/score } \\
\cline { 1 - 2 } \cline { 5 - 6 } Portuguese response & English translation & & 1 to 13 & 14 to 24 \\
\hline discordo fortemente & strongly disagree & & 0 & 3 \\
discordo & disagree & & 1 & 2 \\
concordo & agree & & 2 & 1 \\
concordo fortemente & strongly agree & & 3 & 0 \\
\hline
\end{tabular}

In the internal consistency analysis, the following values of Cronbach's $\alpha$ coefficients were found: $\alpha=0.77$ (95\% CI $0.79,0.81$ ) for the total scale; $\alpha=0.77$ (95\% CI $0.75,0.8$ ) for the Choices dimension; $\alpha=0.68$ (95\% CI $0.64,0.71$ ) for the Modes dimension; $\alpha=0.58$ (95\% CI $0.53,0.63$ ) for the Organization dimension; and $\alpha=0.82$ (95\% CI $0.8,0.84$ ) for the Planning dimension. McDonald's $\omega$ for the total scale was equal to $0 \cdot 83$.

In the reproducibility analysis, the ICC for the total score and for all items are shown in Table 3. The ICC for the total score was 0.82 (95\% CI $0.74,0.87)$, which indicates excellent reliability, and the ICC of the items ranged from 0.40 to 0.75 , which indicates fair to good reliability. The random distribution pattern of differences noted in the Bland-Altman plot (Fig. 4) suggests the 


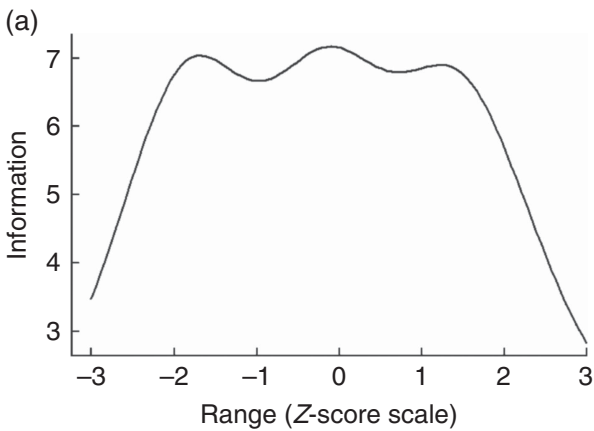

(b)

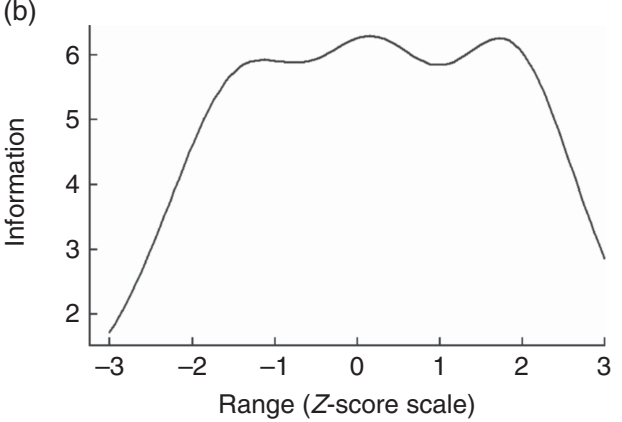

(d)

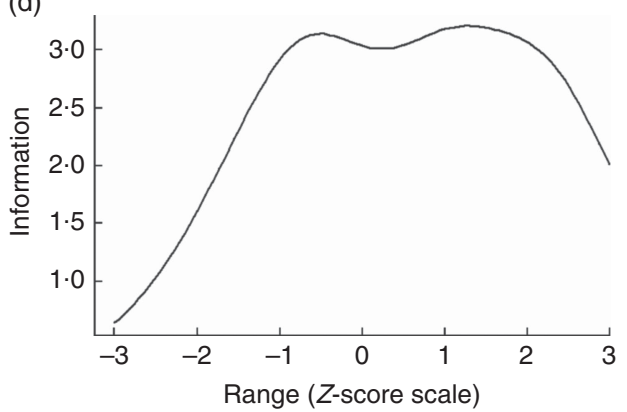

(c)

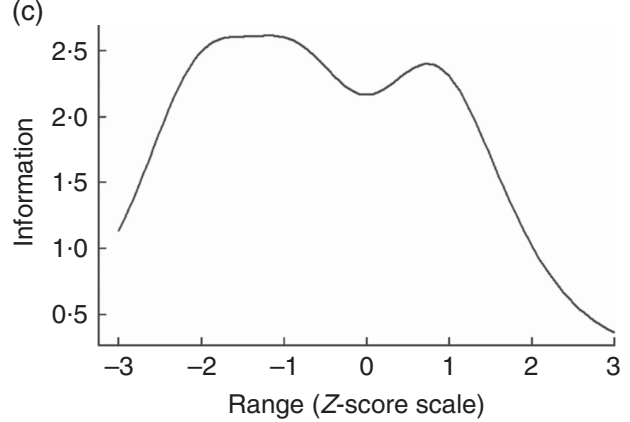

(e)

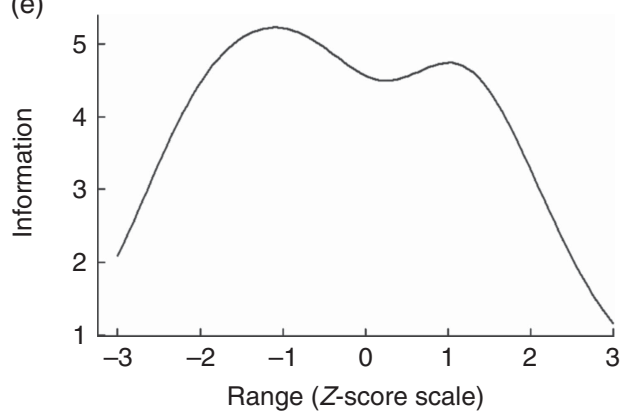

Fig. 3 Test information curves corresponding to the full scale (a) and the Planning (b), Organization (c), Modes (d) and Choices (e) subscales of the scale for measuring healthy eating practices according to the Dietary Guidelines for the Brazilian Population recommendations

absence of possible systematic errors, such as a learning effect in the test.

\section{Discussion}

The objective of the present study was to develop a valid tool to measure healthy eating practices according to the Brazilian Guide recommendations, which was expected to contribute to the evaluation of this instrument. Throughout the elaboration of this scale, the use of the methodological psychometric framework was appropriate for the characteristics of this guide. In studies of this nature, the item development and the content and face validity phases (in which the items are edited) are considered fundamental since they can influence psychometrical property outcomes ${ }^{(26)}$. Despite being an uncommon practice in scale development studies, the review of the scales' items by members of the target population, and not only experts, enables researchers to identify and eliminate potential problems in the scale before it is applied at large ${ }^{(44)}$. In this sense, the methods adopted in the present study to achieve content and face validities were very important for guaranteeing that both the items and the Likert response options were well understood by the target population.

During construct validity, some methodological considerations are important. At the exploratory step, the sample size for the EFA was close to the minimum limit suggested in the literature (five observations per variable). The size of the sample is directly related to the probability of identification of trusty correlation patterns between the variables; the KMO value is an indicator of this (values closer to 1 are better). In this regard, although a factor analysis can be performed with values greater than $0.5^{(30)}$, the KMO value found in the present study $(0.63)$ indicated a diffuse pattern in almost $40 \%$ of the variance between 


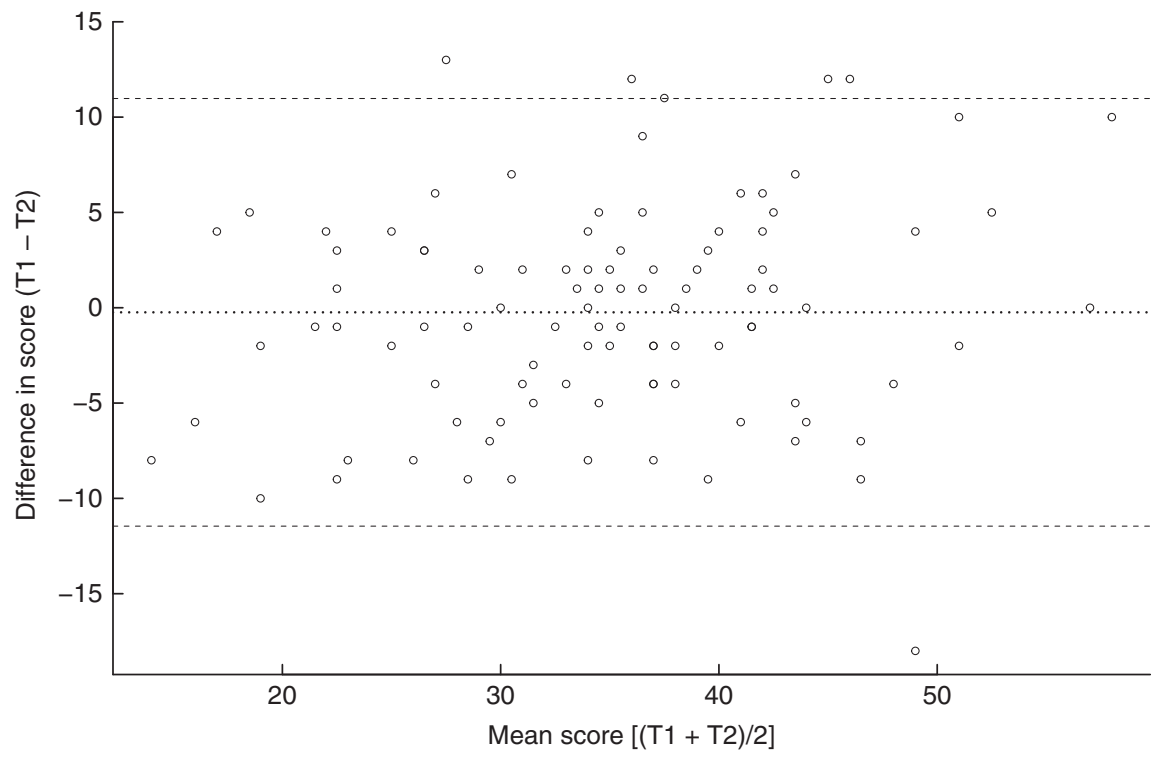

Fig. 4 Bland-Altman plot showing the distribution of the differences between individuals' scores at time 1 (T1) and time 2 (T2) $v$. their mean scores for T1 and T2 (30 d apart) among adults aged 18-60 years $(n 100)$ who completed the scale for measuring healthy eating practices according to the Dietary Guidelines for the Brazilian Population recommendations. . . . represents the mean difference (bias) and - - - - represent the limits of agreement

items, likely due to random errors. For small samples, such as this case, parsimonious interpretation of the obtained results is suggested, since they can be 'superadjusted' (i.e. to generate factors that reflect specific characteristics of the sample) and cannot be extrapolated ${ }^{(28)}$.

In the confirmatory step, both the size and the heterogeneity of the sample were greater than those of the exploratory step, which are good aspects for proceeding with factor analysis because they can increase the diversity of characteristics inherent to the construct of interest ${ }^{(29)}$. Considering the great cultural diversity in Brazilian territory, this sample distribution among the five Brazilian macro-regions was crucial for results generalization. The good fit of the final model validated the model extracted from the EFA since it demonstrated that the same factorial structure can also be fitted even to a heterogeneous population.

Although no previous hypothesis on the dimensionality was established (justifying the adoption of the exploratory step), the multidimensionality of the scale is in line with the complex nature of the healthy diet components recognized by the Guide. Regarding the food and nutrition area, the use of multidimensional approaches has grown as the understanding of diet as a multifaceted phenomenon has broadened. For example, Doustmohammadian et al. ${ }^{(45)}$ and Perry et $a l .{ }^{(46)}$ performed studies with the aim of generating scales to measure 'food literacy', which is a phenomenon known as the ability to plan, chose, prepare and consume food based on the implication of these attributes in a complex dietary system ${ }^{(47)}$. In the current study, the dimensions emerged from the construct validity analysis that represents the core of the three chapters of the Guide that compose the theoretical domains of the scale.
The Choices dimension kept items related to the consumption habits of sugary beverages, ultra-processed snacks and fast foods, which were precisely determined to be the ultra-processed foods most consumed by the Brazilian population, as evidenced in a population budget survey conducted in 2008-2009 to investigate the total energy contribution to the diet ${ }^{(15)}$. This dimension deals specifically with the core recommendation of the Guide, 'Always prefer natural or minimally processed foods and freshly made dishes and meals to ultra-processed foods, ${ }^{\text {,(3), }}$ which refers to the tendency to replace foods from the first group with foods from the second group, as observed by Louzada et al. ${ }^{(13)}$. The direction of opposition between the NOVA groups and the presence of the verb 'prefer' are consistent with the use of a latent variable for measurement given adherence to this recommendation.

The Modes dimension addresses how food consumption and meals occur, specifically in relation to the regularity, attention and characteristics of the environment. Evidence regarding the influence of these factors on the pleasure provided by eating ${ }^{(7,48)}$ and the quantity and quality of the food ingested ${ }^{(49)}$ is increasing. Regarding this latter aspect, inappropriate eating habits seem to be related to the ingestion of ultra-processed foods ${ }^{(14,50)}$, which corroborates the positive correlation found between the Modes and Choices dimensions in the present study.

The Organization dimension is related to the preparation and consumption of meals at home, as indicated by the inclusion of the expression 'in my home' in different items. The influence of the domestic environment on eating habits has been corroborated in the literature; for example, the study by Pachucki et $a l^{(51)}$ found a direct association between diet quality and meals prepared and 
consumed at home by men and inversely between meals consumed outside of home by women in a sample of diabetic individuals. The authors discuss the gender difference in the light of persistent discrepancies in household task overload. This discrepancy was also explored in the study of Hartmann et al. ${ }^{(52)}$, which discussed culinary skills for preparing meals at home. These findings from the literature give rise to future analyses of scores on the scale according to gender, particularly since one of the items in this dimension refers specifically to task sharing.

The Planning dimension is expressed in terms of the acquisition of food, the combination of foods in the form of meals and their consumption. Vidgen and Gallegos ${ }^{(47)}$ found similar components when defining food literacy, which suggested affinity between the Planning dimension and the food literacy attribute. The positive correlation between this dimension and the Organization dimension is plausible from the theoretical perspective, since they are related to similar attributes, although the specificity of the latter manifests itself within the domicile.

The reliability of the total score was satisfactory in the internal consistency analysis for Cronbach's $\alpha$ and McDonald's $\omega$ coefficients. Values of $\alpha$ were slightly lower for Modes and Organization dimensions than for Choices and Planning dimensions, which is likely due to the lower number of items (four items) since the $\alpha$ coefficient is sensitive to the number of variables included in the calculation $^{(53)}$. However, this did not minimize the importance and relevance of these two dimensions within the entire scale but reinforces the fact that this scale must be applied as a whole and its score analysed as the only measure. In the test-retest reliability assessment, a satisfactory agreement was observed between the scores of two time point applications, which suggests a good stability of the instrument. Therefore, the validity and reliability results from the present study raise the potential applicability of this scale in different contexts, including health services, management and scientific research.

In a global panorama, with some exceptions, the actions of evaluation of dietary guidelines have been given in an incipient manner. Surveys conducted in 2011 and 2014 reported that most experiences in this area were performed in isolation with small groups and were directed mainly towards the evaluation of their implementation processes $^{(2,54)}$. Since then, some new experiences in the evaluation of dietary guidelines have been published. For example, Bechtold et al. ${ }^{(55)}$ evaluated population knowledge of the recommendations of the German Dietary Guidelines, and Arentoft et al. ${ }^{(56)}$ and Eriksen et al. ${ }^{(57)}$ evaluated the relationships between adherence to the recommendations of the dietary guidelines from Denmark and the UK, respectively, and specific health outcomes. Given this context, the current study will contribute in an innovative way not only by enabling the establishment of continuous evaluation processes for dietary guidelines, as occurs in USA for instance ${ }^{(58)}$, but also by sharing the experience of developing and validating a tool that measures dimensions that are not directly observable but are part of a healthy eating paradigm.

One limitation of the present study is that convergent validity was not assessed, which would confirm whether the scale measures the eating practices related to the recommendations of the Guide. These validations would be performed, for example, by a comparison between scores on the scale and another measure supposedly correlated with it, such as ultra-processed food consumption, which can be measured through a $24 \mathrm{~h}$ eating recall. For such analysis, new data collection within a study with a design differing from the present study would be necessary. Nunally and Bernstein ${ }^{(26)}$ pointed out that validation is an unending process in which new evidence may reinforce the validity of an instrument or suggest modifications in its composition. Although the construct validity of the scale can be supported both by the theoretical coherence with the Guide and the statistical evidence of model good fit, future analyses in this regard would be very important.

Another limitation is that the sample used in the validation process was not representative of the Brazilian population. However, regional differences were mitigated by the fact that individuals from all Brazilian geographic regions participated in all phases of the study. The electronic data collection for the confirmatory step of construct validity was a decision that might represent a limitation, since psychometric properties identified in questionnaires applied on paper were not necessarily reproduced when the same questionnaires were applied online ${ }^{(59)}$. However, this decision was timely, because it allowed wider participation of individuals from different regions and the possibility of applying the scale through this route, since the validity results were satisfactory. This decision is a factor that can broaden the reach of the tool and therefore its use to evaluate the impact of the Guide.

Finally, a multidimensional self-applied scale was developed and validated that could be administered either on paper or electronically (online). Future studies that assess convergent validity with representative samples from different scenarios in Brazil are important for broadening understanding about the phenomena measured by this tool. The present study is innovative in the context of the impact evaluation of dietary guidelines and contributes not only to assessment of the impact of the Brazilian Guide, but can also inspire other countries to develop and validate instruments specific to their local context. Movements in this regard are important for future research on the actual potential of the dietary guidelines to promote healthy diets patterns in a global context.

\section{Acknowledgements}

Financial support: This study was financed in part by the Coordenação de Aperfeiçoamento de Pessoal de Nível 
Superior, Brasil (CAPES) (finance code 001) and by the Brazilian Ministry of Health (grant number 825680/2015). CAPES and the Brazilian Ministry of Health had no role in the design, analysis or writing of this article. Conflict of interest: None. Authorship: K.T.G. and P.C.J. designed the study; K.T.G. carried out the study, analysed the data and wrote the article; P.C.J. edited the article. Ethics of human subject participation: This study was conducted according to the guidelines laid down in the Declaration of Helsinki and all procedures involving human subjects were approved by the Comitê de Ética em Pesquisa da Faculdade de Saúde Pública da Universidade de São Paulo (protocol number 1.687.651). Written informed consent was obtained from all subjects.

\section{Supplementary material}

To view supplementary material for this article, please visit https://doi.org/10.1017/S1368980018004123

\section{References}

1. Food and Agriculture Organization of the United Nations/ World Health Organization (1998) Preparation and Use of Food-Based Dietary Guidelines. Report of a Joint FAO/WHO Consultation, Nicosia, Cyprus, 1995. WHO Technical Report Series no. 880. Geneva: WHO.

2. Food and Agriculture Organization of the United Nations (2014) El Estado de las Guías Alimentarias Basadas en Alimentos en América Latina y el Caribe: 21 ãnos después de la Conferencia Internacional sobre Nutrición. Rome: FAO.

3. Brazil Ministry of Health (2014) Dietary Guidelines for the Brazilian Population. Brasília, DF: Ministry of Health.

4. Monteiro CA, Cannon G, Moubarac J-C et al. (2015) Dietary guidelines to nourish humanity and the planet in the twenty-first century. A blueprint from Brazil. Public Health Nutr 18, 2311-2322.

5. Jacobs DR \& Tapsell LC (2013) Food synergy: the key to a healthy diet. Proc Nutr Soc 72, 200-206.

6. Fischer CG \& Garnett T (2016) Plates, Pyramids, Planet. Developments in National Healthy and Sustainable Dietary Guidelines: A State of Play Assessment. Rome: FAO and the Food Climate Research Network at the University of Oxford.

7. Oliveira MS da S \& Silva-Amparo L (2018) Food-based dietary guidelines: a comparative analysis between the Dietary Guidelines for the Brazilian Population 2006 and 2014. Public Health Nutr 21, 210-217.

8. Monteiro CA, Cannon G, Moubarac JC et al. (2018) The UN Decade of Nutrition, the NOVA food classification and the trouble with ultra-processing. Public Health Nutr 21, 5-17.

9. Levy RB, Claro RM, Mondini L et al. (2012) Regional and socioeconomic distribution of household food availability in Brazil, in 2008-2009. Rev Saude Publica 46, 6-15.

10. Martins APB, Levy RB, Claro RM et al. (2013) Increased contribution of ultra-processed food products in the Brazilian diet (1987-2009). Rev Saude Publica 47, 656-65.

11. Canella DS, Levy RB, Martins APB et al. (2014) Ultraprocessed food products and obesity in Brazilian households (2008-2009). PLoS One 9, e92752.

12. Rauber F, Campagnolo PDB, Hoffman DJ et al. (2015) Consumption of ultra-processed food products and its effects on children's lipid profiles: a longitudinal study. Nutr Metab Cardiovasc Dis 25, 116-122.

13. Louzada ML da C, Martins APB, Canella DS et al. (2015) Ultra-processed foods and the nutritional dietary profile in Brazil. Rev Saude Publica 49, 38. doi: 10.1590/S00348910.2015049006132

14. Louzada ML da C, Baraldi LG, Steele EM et al. (2015) Consumption of ultra-processed foods and obesity in Brazilian adolescents and adults. Prev Med 81, 9-15.

15. Instituto Brasileiro de Geografia e Estatística (2010) Pesquisa de Orçamentos Familiares 2008-2009. Aquisição Alimentar Domiciliar per Capita: Brasil e Grandes Regiões. Rio de Janeiro, RJ: IBGE.

16. Food and Agriculture Organization of the United Nations (2007) Developing Food-based Dietary Guidelines. A Manual from the English-Speaking Caribbean. Rome: FAO.

17. Verly Junior E, de Carvalho AM, Fisberg RM et al. (2013) Adherence to the food guide for the Brazilian population. Rev Saude Publica 47, 1021-1027.

18. Andrade J \& Andrade J (2016) Technical Note: Methods for Teaching and Evaluating Food-Based Dietary Guidelines. http://ingenaes.illinois.edu/dp-tn/ (accessed June 2018).

19. DeVellis RF (2017) Scale Development: Theory and Applications, 4th ed. Los Angeles, CA: SAGE Publications, Inc.

20. Nadler JT, Weston R \& Voyles EC (2015) Stuck in the middle: the use and interpretation of mid-points in items on questionnaires. J Gen Psychol 142, 71-89.

21. Streiner DL, Norman GR \& Cairney J (2014) Health Measurement Scales: A Practical Guide to Their Development and Use, 5th ed. Oxford: Oxford University Press.

22. Pasquali L (2003) Psicometria: Teoria dos Testes na Psicologia e na Educação, 5th ed. Petrópolis, RJ: Vozes.

23. Rubio DM, Berg-Weger M, Tebb SS et al. (2003) Objectifying content validity: conducting a content validity study in social work. Soc Work Res 27, 94-104.

24. Guibu IA, de Moraes JC, Junior AAG et al. (2017) Main characteristics of patients of primary health care services in Brazil. Rev Saude Publica 51, Suppl. 2, 17 S.

25. Ritchie J, Lewis J \& Elam G (2003) Designing and selecting samples. In Qualitative Research Practice: A Guide for Social Science Students and Researchers, pp. 77-108 [J Ritchie and J Lewis, editors]. London: SAGE Publications Ltd.

26. Nunally JC \& Bernstein IH (1994) Psychometric Theory, 3rd ed. New York: McGraw-Hill.

27. Core Team R (2017) R: A Language and Environment for Statistical Computing. Vienna: R Foundation for Statistical Computing.

28. Hair A, Black WC, Babin BJ et al. (2009) Análise Multivariada de Dados, 6th ed. Porto Alegre, RS: Bookman.

29. Brown TA (2015) Confirmatory Factor Analysis for Applied Research Methodology in the Social Sciences, 2nd ed. New York: Guilford Press.

30. Field A (2009) Descobrindo a Estatistica Usando o SPSS-2, 2nd ed. Porto Alegre, RS: Artmed.

31. Revelle W (2018) psych: Procedures for Personality and Psychological Research. Evanston, IL: Northwestern University; available at https://CRAN.R-project.org/pack age $=$ psych Version $=1.8 .10$

32. Holgado-Tello FP, Moscoso SC, Barbero-Garcia I et al. (2010) Polychoric versus Pearson correlations in exploratory and confirmatory factor analysis of ordinal variables. Qual Quant 44, 153-166.

33. Rosseel Y (2012) lavaan: an R package for structural equation modeling. J Stat Softw 48, 1-36.

34. Li CH (2016) Confirmatory factor analysis with ordinal data: comparing robust maximum likelihood and diagonally weighted least squares. Behav Res Methods $\mathbf{4 8}$, 936-949. 
35. Browne MW \& Cudeck R (1992) Alternative ways of assessing model fit. Soc Methods Res 21, 230-258.

36. Hu LT \& Bentler PM (1999) Cutoff criteria for fit indexes in covariance structure analysis: conventional criteria versus new alternatives. Struct Equ Modeling 6, 1-55.

37. Barros CG, Swardfager W, Moreno S et al. (2017) Assessing music perception in young children: evidence for and psychometric features of the M-factor. Front Neurosci 11, 18.

38. Reise SP (2012) The rediscovery of bifactor measurement models. Multivariate Behav Res 47, 667-696.

39. Viladrich C, Angulo-Brunet A \& Doval E (2017) A journey around alpha and omega to estimate internal consistency reliability. Ann Psychol 33, 755-782.

40. Dunn TJ, Baguley T \& Brunsden V (2014) From alpha to omega: a practical solution to the pervasive problem of internal consistency estimation. Br J Psychol 105, 399-412.

41. Fleiss JL \& Cohen J (1973) The equivalence of weighted kappa and the intraclass correlation coefficient as measures of reliability. Educ Psychol Meas 33, 613-619.

42. Koo TK \& Li MY (2016) A guideline of selecting and reporting intraclass correlation coefficients for reliability research. J Chiropr Med 15, 155-163.

43. Giavarina D (2015) Understanding Bland Altman analysis. Biochem Med (Zagreb) 25, 141-151.

44. Morgado FFR, Meireles JFF, Neves CM et al. (2017) Scale development: ten main limitations and recommendations to improve future research practices. Psicologia: Reflexão e Crítica 30, 3. doi: 10.1186/s41155-016-0057-1.

45. Doustmohammadian A, Omidvar N, KeshavarzMohammadi N et al. (2017) Developing and validating a scale to measure Food and Nutrition Literacy (FNLIT) in elementary school children in Iran. PLoS One 12, e0179196.

46. Perry EA, Thomas H, Samra HR et al. (2017) Identifying attributes of food literacy: a scoping review. Public Health Nutr 20, 2406-2415.

47. Vidgen HA \& Gallegos D (2014) Defining food literacy and its components. Appetite 76, 50-59.

48. Scagliusi FB, da Rocha Pereira P, Unsain RF et al. (2016) Eating at the table, on the couch and in bed: an exploration of different locus of commensality in the discourses of Brazilian working mothers. Appetite 103, 80-86.

49. Cohen DA \& Farley TA (2008) Eating as an automatic behavior. Prev Chronic Dis 5, A23.

50. Ludwig DS (2011) Technology, diet, and the burden of chronic disease. JAMA 305, 1352-1353.

51. Pachucki MC, Karter AJ, Adler NE et al. (2018) Eating with others and meal location are differentially associated with nutrient intake by sex: the Diabetes Study of Northern California (DISTANCE). Appetite 127, 203-210.

52. Hartmann C, Dohle S \& Siegrist M (2013) Importance of cooking skills for balanced food choices. Appetite $\mathbf{6 5}$, 125-131.

53. Streiner DL (2003) Being inconsistent about consistency: when coefficient alpha does and doesn't matter. J Pers Assess 80, 217-222.

54. Brown KA, Timotijevic L, Barnett J et al. (2011) A review of consumer awareness, understanding and use of food-based dietary guidelines. Br J Nutr 106, 15-26.

55. Bechthold A, Wendt I, Laubach B et al. (2017) Consumers' awareness of food-based dietary guidelines in Germany. Results of a representative survey. Ernabrungs Umschau 64, 112-119.

56. Arentoft JL, Hoppe C, Andersen EW et al. (2018) Associations between adherence to the Danish Food-Based Dietary Guidelines and cardiometabolic risk factors in a Danish adult population: the DIPI study. Br J Nutr 119, 664-673.

57. Eriksen R, Gibson R, Lamb K et al. (2018) Nutrient profiling and adherence to components of the UK national dietary guidelines association with metabolic risk factors for CVD and diabetes: Airwave Health Monitoring Study. Br J Nutr 119, 695-705.

58. Krebs-Smith SM, Pannucci TE, Subar AF et al. (2018) Update of the Healthy Eating Index: HEI-2015. J Acad Nutr Diet 118, 1591-1602.

59. Hirsch O, Hauschild F, Schmidt MH et al. (2013) Comparison of web-based and paper-based administration of ADHD questionnaires for adults. J Med Internet Res 15, e47. 